\title{
The Role of Male Involvement in Modern Family Planning Utilization and Associated Factors in Arba Minch Town, Gamo Gofa Zone, Ethiopia
}

\author{
Gemechu Kejela, Girma Mira, Belete Gaga, Aman Muktar, Behailu Ololo, Shanko Bezabehe \\ Department of Public Health, College of Medicine and Health Science, Arba Minch University, Arba Minch, Ethiopia \\ Email address: \\ gemechukejela86@gmail.com (G. Kejela),girmamira@gmail.com (G. Mira), beletegaga@gmail.com (B. Gaga), \\ muktaraman@yahoo.com (A. Muktar),obehailu@gmail.com (B. Ololo), bezabeheshanko@gmail.com (S. Bezabehe)
}

\section{To cite this article:}

Gemechu Kejela, Girma Mira, Belete Gaga, Aman Muktar, Behailu Ololo, Shanko Bezabehe. The Role of Male Involvement in Family Planning Utilization and Associated Factors in Arba Minch Town, Gamo Gofa Zone, Ethiopia. European Journal of Preventive Medicine. Vol. 5, No. 4, 2017, pp. 39-44. doi: 10.11648/j.ejpm.20170504.11

Received: May 2, 2017; Accepted: May 20, 2017; Published: July 14, 2017

\begin{abstract}
Introduction: Men often have higher decision making power in matters such as sexual relations, family size, and seeking health care than women. On the contrary, women carry a disproportionate amount of responsibility for reproductive health matters including family planning. Even though women receive the bulk of reproductive health services, gender dynamics makes women powerless. Reproductive health matters in its broader sense should be a concern for all not for just that of women; and it needs the attention of men, entire family and the society at large. Despite this, men involvement in family planning utilization is low in Ethiopia. Objective: The main aim of this study is to assess the role of male involvement in family planning utilization and associated factors in Arba minch-town, Gamo Gofa zone, Ethiopia. Methods: A community based cross-sectional study was conducted in Arba-minch town among 406 married men. The data was collected by face-to-face interview using pre-tested structured questionnaire. Sampling units (households that fulfill the inclusion criteria) were selected by using simple random sampling method. Verbal consent was obtained from respondents by explaining the objective of the study. The questioner was developed in English then translated to local language for actual data collection. Data was cleaned, coded and entered into computer and analyzed using SPSS version 20.0. Binary and multivariable logistic regression analysis was done at $95 \%$ CI and variables with $\mathrm{p}$-value of $<0.05$ at multivariable logistic regression were considered as significant predictors of the outcome variable. The findings of the study were presented in text, tables and charts. Result: The result of this study shows that male involvement in modern contraceptive utilization is $68 \%$. Respondents who were knowledgeable on modern family planning methods were 2 times more likely to involve in family planning utilization compared to those who have no knowledge (AOR $[95 \% \mathrm{CI}]=2.0[1.397,3.992])$. Respondents whose desired number of children is less than or equal to three were five times more likely involve in modern family planning utilization (AOR $[95 \% \mathrm{CI}]=5.0[0.192,0.957]$ ). In addition, respondents who are illiterate were $85 \%$ less likely to involve in modern family planning utilization compared to those with educational status of diploma and above (AOR [95\% CI] $=0.15$ [2.299, 17.738]). Conclusion and recommendation: In this study, male involvement in modern contraceptive utilization is slightly high compared to other studies conducted in the country. Male involvement on modern contraceptive utilization is largely influenced by men knowledge on modern contraceptive methods, level of education and desired number of children. Family planning Information, Education and communication should be given for men to increase their involvement in modern contraceptive utilization.
\end{abstract}

Keywords: Family Planning, Male, Involvement, Utilization, Arba Minch

\section{Introduction}

Family planning refers to a conscious effort by a couple to limit or space the number of children they have through the use of contraceptive methods. Contraceptive methods are classified as modern or traditional methods, the modern methods include female sterilization, male sterilization, pill, Intrauterine Device (IUD), inject able, implants, male 
condom, female condom, diaphragm/foam/jelly, while traditional methods includes; standard days method, lactation amenorrhea method (LAM), methods such as rhythm (periodic abstinence), withdrawal, and folk methods $[1,2]$.

The program of action adopted by the International Conference on Population and Development (ICPD) held in Cairo 1994 notes that, men's should share responsibility and promote their active involvement in responsible parenthood, sexual and reproductive behavior, including family planning; pre-natal, maternal and child health; prevention of sexually transmitted infections; and prevention of unwanted and highrisk pregnancies. In addition, use of male methods is one important aspect of male involvement in family planning [1].

In the past, family-planning programs have focused attention primarily on women, because of the need to free women from excessive child-bearing, and to reduce maternal and infant mortality through the use of modern methods of contraception despite child bearing is the outcome of both partners in a conjugal union and men together with women play key roles in reproductive health decision making. This focus on women has reinforced the belief that family planning is largely a woman's business, with the man playing a very peripheral role [3].

The present contribution of male methods to the total Contraceptive Prevalence Rate (CPR) is strikingly low. Worldwide, one-third of the eligible couples using family planning rely on methods (vasectomy, condom, withdrawal and periodic abstinence) which require full male co-operation [4]. Although there has been overall increase in the level of contraceptive prevalence, but use of male methods is likely to remain static in most of the developing countries [5]. Even in developing countries like China, Thailand and Indonesia with high level of contraceptive prevalence, the use of male methods is very low [6].

Reproductive health in its broader sense and FP in particular should be a concern for all not for just that of women and it needs the attention of men, entire family and the society at large [7]. However, women carry a disproportionate amount of responsibility for reproductive health matters including FP particularly in developing countries. Although women receive the bulk of reproductive health services, gender dynamics can render women powerless [8]. Men often have higher decision making power in matters such as sexual relations, family size, and seeking health care than women [9]. Recently most countries, including Ethiopia, are trying to adapt the new initiative of involving men in family planning programs [10].

Despite this initiative the fact on which men characteristics combined to women factors that are influential in modifying family planning use are not well known. Therefore, the roles of males along with women factors that influence the utilization of family planning methods by couples need thorough study in order to develop appropriate interventions to achieve the desired outcome of family planning program. So, the main aim of this study is to assess male involvement in family planning utilization and associated factors among married men in Arba-minch town Gamo Gofa zone, SNNRG,
Ethiopia.

\section{Methods}

\subsection{Study Design and Setup}

Community based cross sectional study was conducted among 406 married men living in Arba-minch town, SNNPRS, Ethiopia, from September 15/2016 to January $15 / 2017$. Arba Minch town is located at $505 \mathrm{~km}$ from Addis Ababa and $275 \mathrm{~km}$ from regional capital city of Hawassa. It has a population size of 108,965. Among these, 53,393 (49\%) are males and 55,572 (51\%) are females.

Currently married men living with their wives in Arbaminch town for at least six months prior to the study period were the source population and currently married men, living with their wives in Arba Minch town for at least six month and fulfill the inclusion criteria were the study population.

\subsection{Sample Size Determination and Sampling Procedure}

Sample size was calculated using single population proportion formula by considering the following assumptions; proportion of currently married men who discussed about the issues of family planning with their wife of $59.8 \%$ [11], 95\% confidence level, 5\% margin of error, and an addition of $10 \%$ non-response rate. The final sample size was computed to be 406 currently married men.

To get the required sample, first, from the four sub cities of Arba-minch town, Nechsar sub city was selected by using lottery method. Then Pre-survey was conducted in the selected sub-city to identify households with married men in reproductive age group. Finally, households with study samples were selected using systematic sampling method. The first house included in the study was selected by lottery method. If there was no respondent (the house was closed), repeated visit up to three times was conducted.

\subsection{Data Collection Tools and Quality Control}

Data was collected by using structured pretested interview administered questionnaire. The questionnaire was prepared in English and translated local language and back to English by the language experts in order to maintain consistency. To ensure the quality of the data, training was given for data collectors and supervisors, pretest was conducted among households in non-selected sub-city and close supervision of the data collection was conducted.

\subsection{Measurement}

The dependent variable in this study is status of men involvement in family planning which can be measured as; those who are participating at least in either of; communicating about family planning such as spacing, limiting, on the choice of family planning methods and fertility decision making like desired number of children with 
their wives within the previous month prior to the period of data collection and/or; using modern FP method either the respondents or their wives after getting the respondents (husbands) approval (or joint approval) during the period of data collection.

\subsection{Data Processing and Analysis}

Data were entered into EPI data version 3.02 and exported to SPSS version 20.0 for analysis. Frequencies of different variables were determined and followed by cross tabulations to compare their frequencies. Binary logistic regression was conducted for dependent and independent variables and crude odds ratio (COR) with $95 \%$ confidence interval was estimated to assess the association between dependent and in dependent variables. Then variables with $p$-value of $<0.3$ at binary logistic regression were taken into multivariable logistic regression analysis to assess their association with dependent variable. Hosmer-Lemeshow goodness-of-fit with stepwise (backward elimination) was used to test for model fitness. Adjusted odds ratio (AOR) with 95\% confidence interval was estimated to assess the presence of association at multivariable logistic regression. Variables with p-value of $<$ 0.05 at multivariable logistic regression were considered as statistically significant predictors of men involvement in family planning utilization. Finally, the analyzed data were summarized using text, tables and charts.

\subsection{Ethical Considerations}

Ethical clearance was obtained from Institutional Research Ethics Review Committee of Arba Minch University College of medicine and health sciences. Letter of permission was obtained from administration of the selected sub city. Signed consent was obtained from the respondent through addressing the necessary explanation about the purpose of the study and its procedure, assurance of confidentiality, privacy and the right to with draw the participation at any time without any consequences. Participants were also assured that, they did not face any problem for their participation in the study.

\section{Result}

\subsection{Demographic and Socioeconomic Characteristics of the Respondent}

All the selected 406 married men participants responded to questioner making the response rate of $100 \%$. The mean age of the study participants was 26.11 (SD+3.61) years. Majority, $243(60 \%)$ of the respondents were in the age group of $25-29$ years and $2.5 \%$ were in the age-group of 15-19 years. One hundred thirty one $(32 \%)$ of the respondents cannot read and write, $112(27.5 \%)$ can read and write but no formal education, $96(23.6 \%)$ had Primary and secondary education (1-12 grade) and $67(16 \%)$ of the respondents had higher educational level (diploma and above). Of the participants, 242 (59.2\%) were Governmental employee followed by merchant 74 (18.2\%). Seventy five percent of the respondents were Gamo followed by Gofa $(22 \%)$ (Table 1$)$.

Table 1. Socio-demographic characteristics of the study participants in Arba Minch town, SNNPR, Ethiopia, 2017.

\begin{tabular}{llll}
\hline Variable & Category & Frequency & Percent \\
\hline \multirow{3}{*}{ Age of the } & $15-19$ & 10 & 2.5 \\
husband & $20-24$ & 119 & 29.3 \\
& $25-29$ & 243 & 60 \\
& $>=30$ & 33 & 8 \\
Ethnicity & Gamo & 303 & 74.6 \\
& Gofa & 74 & 22 \\
& Wolaita & 24 & 18 \\
Occupation the & Others & 5 & 1.2 \\
respondent's & House wife & 197 & 48.5 \\
wife & Govehant & 127 & 31.3 \\
& Others & 67 & 16.5 \\
Occupation of & Governmental employee & 242 & 3.7 \\
the husband & Merchant & 74 & 59.2 \\
& Daily laborer & 68 & 18.2 \\
\hline
\end{tabular}

More than half, 211 (52\%) of the respondents wife were in the age group of 20-24 years and only $16(4 \%)$ are in the age group of 15-19 years (Figure 1).

More than half of the respondents, 227 (56.2\%) were protestant followers, followed by orthodox in religion $39 \%$. (Figure 2)

\section{Respondant's wife age inpercent}

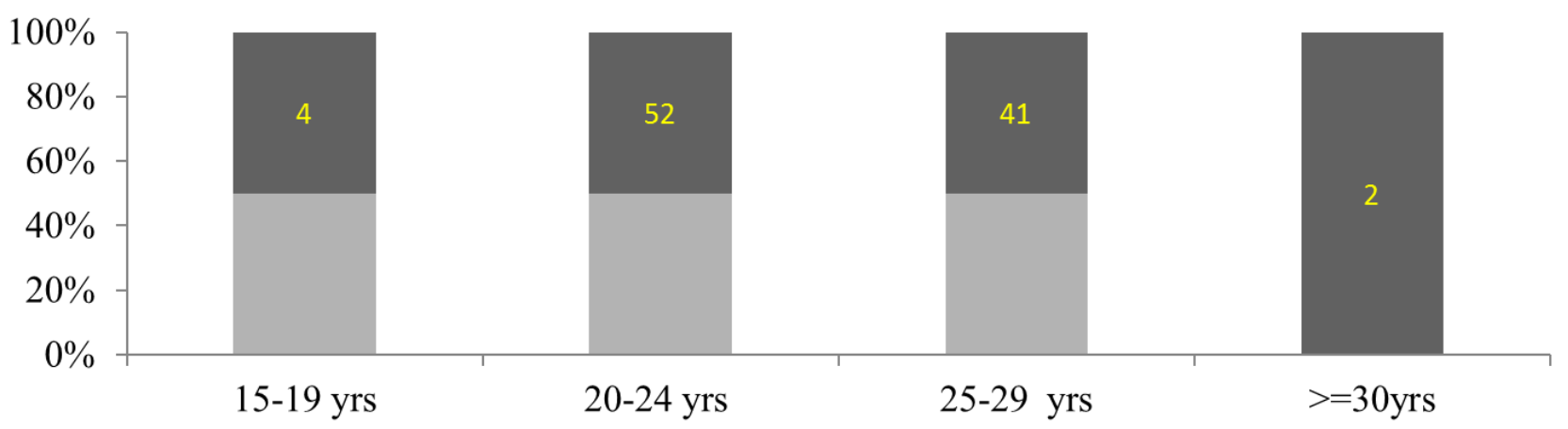

Figure 1. Age of the respondent's wife in Arba-minch town, SNNPR, Ethiopia, 2017. 


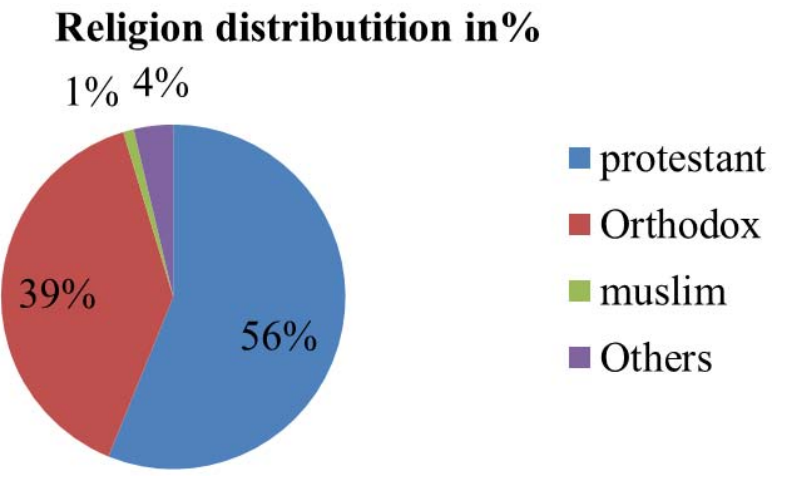

Figure 2. Religion of the respondents in Arba Minch town, SNNPR, Ethiopia, 2017.

\subsection{Husband-Wife Communication About Modern Contraceptive Methods and Utilization}

A total of $68 \%$ of the respondent discussed the issue of family planning with their wife within one month prior to data collection. Of these, $66.6 \%$ discussed the issue of family planning only one times and the rest discussed two and above. The most frequently mentioned topic of discussion was about birth spacing $(85 \%)$. The current utilization of modern family planning was $195(48 \%)$ all of the users are respondent's wife, of these most commonly used methods are injectable $246(60.5 \%)$ and then pills $133(32.5 \%)$. From the current contraceptive users, $78.5 \%$ were approved by their husband (Table 2).

Table 2. Husband-wife Communication about issues of modern contraceptive methods utilization in Arba Minch town, SNNPR, Ethiopia, 2017.

\begin{tabular}{|c|c|c|c|}
\hline Variables & Category & Frequency & Percent \\
\hline \multirow{3}{*}{$\begin{array}{l}\text { Have you discussed about the issue of family planning with your wife within one month prior the data } \\
\text { collection }\end{array}$} & Yes & 276 & 68 \\
\hline & No & 130 & 32 \\
\hline & pills & 133 & 32.8 \\
\hline \multirow{3}{*}{ Using Methods of modern family planning by the respondent's wife. } & Inject able & 246 & 60.5 \\
\hline & Implants & 23 & 5.6 \\
\hline & Others & 4 & 1 \\
\hline \multirow{2}{*}{$\begin{array}{l}\text { The respondent's wife currently using modern family planning method approved by her has band. } \\
\text { /approved for her to use? }\end{array}$} & approved & 319 & 78.5 \\
\hline & My self & 109 & 26.8 \\
\hline \multirow[t]{2}{*}{ Decision makers on the types Family planning to be used } & My wife & 158 & 3.2 \\
\hline & Both of us & 140 & 34 \\
\hline \multirow{2}{*}{ If your wife requests you to use male modern family planning method, what would be your response? } & Approve & 67 & 16.5 \\
\hline & Disapprove & 339 & 83.5 \\
\hline \multirow{2}{*}{ Desired number of children } & 1-3 children & 227 & 46 \\
\hline & $\geq 4$ children & 219 & 54 \\
\hline
\end{tabular}

\subsection{Knowledge About Modern Contraceptive Methods of Respondents}

The prevalence of knowledge on modern family planning method in this study was $92 \%$. From the respondents, the most commonly known, 205 (51\%) was injectable followed by pills in (36.4\%). Almost all of the respondents, 394 (97\%) have heard about modern family planning methods and the source of information was mass media 220 (54\%) followed by health institution 147 (37.3\%) (Table 3).

Table 3. Knowledge about modern contraceptive methods among respondents in Arba Minch town, SNNPR, Ethiopia.

\begin{tabular}{|c|c|c|c|}
\hline Variables & category & Frequency & Percent \\
\hline \multirow{5}{*}{ Do you know any modern contraceptive method } & pills & 112 & 36.4 \\
\hline & inject able & 205 & 51 \\
\hline & condom & 24 & 5.9 \\
\hline & implant & 16 & 3.9 \\
\hline & IUCD & 1 & 0.2 \\
\hline \multirow{2}{*}{$\begin{array}{l}\text { Respondant sKnowledge on modern family planning methods knew at least one contraceptive } \\
\text { methods o }\end{array}$} & yes & 373 & 92 \\
\hline & no & 34 & 8 \\
\hline Heard about modern contraceptives & No & 12 & 3 \\
\hline \multirow{4}{*}{ Source of information } & Health institution & 147 & 37.3 \\
\hline & Mass media (Tv/radio) & 220 & 54 \\
\hline & Friends & 30 & 7.3 \\
\hline & others & 9 & 2.3 \\
\hline
\end{tabular}

\subsection{Predictor of Male Involvement on Modern Contraceptive Practice}

In multi-variable logistic regression, Knowledge on modern family planning was significantly associated with male involvement in family planning utilization, in that, respondents who were knowledgeable on modern family planning methods were 2 times more likely to involve in family planning utilization compared to those who have no knowledge on modern family planning methods (AOR [95\% $\mathrm{CI}]=2.0[1.397,3.992])$. 
Desired number of children there was significantly associated with the out-come variable, in that, respondents whose desired number of children is less than or equal to three were five times more likely involve in modern family planning utilization (AOR $[95 \% \mathrm{CI}]=5.0[0.192,0.957])$.

Educational status of the respondents was significantly associated with the involvement in modern family planning utilization, in that, respondents who are illiterate were $85 \%$ less likely to involve in modern family planning utilization compared to those with educational status of diploma and above (AOR $[95 \%$ CI $]=0.15[2.299,17.738]$ ). Respondents who can read and write were $55 \%$ less likely to involve in modern family planning utilization compared to those who have educational level of diploma and above (AOR [95\% CI] $=0.57[1.113,3.971])$. In addition, respondents who have educational level of primary and secondary were $71 \%$ less likely to involve in modern family planning utilization compared to those who have diploma and above education $($ AOR $[95 \%$ CI $]=0.84[1.023,3.739])($ Table 4$)$.

Table 4. Factors associated with male involvement in modern family planning utilization in Arba-minch town, SNNPR, Ethiopia, 2017.

\begin{tabular}{|c|c|c|c|c|c|}
\hline \multirow{2}{*}{ Variable } & \multirow{2}{*}{ Category } & \multicolumn{2}{|c|}{ Male Involvement } & \multirow{2}{*}{$\operatorname{AOR}[95 \% \mathrm{CI}]$} & \multirow{2}{*}{ P-Value } \\
\hline & & Yes & No & & \\
\hline \multirow{3}{*}{$\begin{array}{l}\text { Knowledge on modern family } \\
\text { planning methods }\end{array}$} & Yes & 258 & 114 & $2.0(1.397,3.992)^{*}$ & 0.001 \\
\hline & No & 18 & 16 & 1 & \\
\hline & illiterate & 51 & 32 & $0.8(0.518,6.225)$ & 0.35 \\
\hline Respondent's wives & able to read and write & 78 & 23 & $1.9(0.203,1.108)$ & 0.08 \\
\hline \multirow[t]{3}{*}{ Educational status } & Primary school and secondary(1-12) & 95 & 53 & $1(0.250,1.369)$ & 0.21 \\
\hline & Higher educational status & 41 & 23 & 1 & \\
\hline & House wife & 67 & 130 & $0.2(0.210,1.375$ & 0.06 \\
\hline \multirow[t]{2}{*}{ Wives occupational status } & Merchant & 81 & 46 & $0.9(0.940,4.519)$ & 0.07 \\
\hline & Governmental employee & 54 & 28 & 1 & \\
\hline \multirow{3}{*}{ Desired number of children } & 1-3 children & 192 & 53 & $5.0(0.192,0.957)^{*}$ & 0.03 \\
\hline & $\geq 4$ children & 94 & 67 & 1 & \\
\hline & Illiterate & 52 & 79 & $0.15(2.299,17.738)^{*}$ & 0.001 \\
\hline \multirow{3}{*}{ Educational status of the respondents } & Able to read and write & 64 & 32 & $0.45(1.113,3.971)^{*}$ & 0.04 \\
\hline & Primary education and secondary school(1-12) & 63 & 49 & $0.29(1.023,3.739)^{*}$ & 0.02 \\
\hline & Diploma and above & 53 & 12 & 1 & \\
\hline
\end{tabular}

N. B: *=Statistically significant association at p-value of $<0.05$.

\section{Discussion}

In this study, male involvement in modern contraceptive utilization was $68 \%$. Male involvement was more common among those who are knowledgeable on modern contraceptive methods, who have low desired number of children and who have higher educational level.

Male involvement in modern contraceptive utilization in this study is higher than study conducted in Wolaita Sodo town $(60 \%)$ [11]. Similarly the finding is higher than study conducted in Hosanna town (48\%) [12]. This discrepancy may be due to time variation, increased awareness of the community about modern contraception, and increased access to male oriented family planning information and services at health settings. However, the finding of this study is lower than study conducted in Nigeria (89\%) [13]. The reason may be due to socio-demographic variation between the two countries.

In this study, male involvement in modern contraceptive utilization was significantly associated with the knowledge of modern contraceptive methods. This finding is similar with the findings of the studies conducted in Sub-Saharan Africa [14], Wolaita Sodo town [11], Hosanna town [12] and Gondar [15]. This may be due to increment in utilization and concern as they obtained adequate information about the available methods.

This study finding showed that the level of education was significantly associated with male involvement on modern contraceptive utilization. The participants, who are unable to write and read, able to read and write, and primary and secondary school were $85 \%, 55 \%$ and $71 \%$ less likely to involve in modern contraceptive utilization respectively than those who have higher educational level. This finding is higher than study conducted in Bangladesh [16] and Gondar [15]. This may be due to time variation, different methodology used and increment of knowledge on family planning through time.

In this study, desired number of children is associated with male involvement in modern contraceptive utilization. Men who desire fewer children are more likely involve in modern contraceptive utilization compared to those who desire more children. This finding is similar with the study conducted in Gondar, Wolaita Sodo and Hosanna $[15,11,12]$. This may be due to, those husbands who need to limit the number of their children need more information about different methods and they may also encourage their wives to utilize the method.

\section{Conclusion and Recommendation}

The prevalence of male involvement in modern contraceptive methods utilization was $68 \%$. Factors associated with male involvement in modern contraceptive methods utilization in this study includes; knowledge on modern contraceptive methods, desired number of children and level of education.

Family planning Information, Education and communication (IEC) should be given for men to increase 
their involvement in modern contraceptive utilization. Community sensitization programs aimed at improving male involvement in family planning should be provided by governmental and nongovernmental agencies. Involving men along with women in encouraging communication and joint decision making on issues like family size and reproduction can help to exercise their responsibility and address their concerns towards family planning within their family.

\section{Conflict of Interest}

The authors declare that they have no conflict of interest regarding the publication of the paper.

\section{Authors' Contribution}

All authors wrote the proposal, participated in data collection, analyzed the data and drafted the paper, approved the proposal with great revisions and revised subsequent drafts of the paper. In addition, all authors contributed in the designing of the methodology, write-up and read and approved the final manuscript.

\section{Acknowledgement}

Authors would like to thank Arba Minch University, College of medicine and health sciences for initiating us to conduct this study and financial support. Deep appreciations have gone to Arba Minch town administration office. Special thanks to all study respondents, data collectors, supervisors and all peoples who involved in the study directly or indirectly.

\section{References}

[1] UNICEF progress for children: A Report Card on Maternal Mortality. Number 7, September 2011.

[2] International Planned Parenthood Federation (2011). Male Involvement in Family Planning utilization.

[3] John C. Caldwell and Pat Caldwell. High fertility in subSaharan Africa. Scientific journal of America 1990; 262 (5): $118-8$.
[4] Akrinnola, B. and S. Susheela, Couple's fertility and contraception decision making in developing countries. J. Int. Fam. Plan. Perspective, 1998: 24 (1): 18-40.

[5] Ross J, Stover J, Adelaja D. Profiles for family planning and reproductive health programs. $2^{\text {nd }}$ Edition. USA. 2009.

[6] World Population Prospects: The 2004 Revision Population database.

[7] Ezeh AC, Serous M, Raggers H. Men's fertility, contraceptive use and reproductive preference. Demographic and Health Survey, Comparative Studies No. 18 Maryland: Macro International Inc, 2010.

[8] Berhane Y. Male involvement in reproductive health. Ethiopian J. Health Dev. 2006: 20 (3): 135-136.

[9] RHM, 2009. Men and Reproductive Health Overview. RHM archives, Retrieved from: http://www.rho.org/ html/menrhlinks.html.

[10] Cald W and P. Cald-Well. Cultural forces tending to sustain high fertility in population growth and reproduction in SubSaharan Africa technical analysis of fertility and consequences. Washington D. C. World Bank, 1990: pp: 199214.

[11] Wondimu A, Addisse A. The Involvement of Men in Family Planning: An Application of Trans-theoretical Model in Wolaita Soddo Town South Ethiopia. AJMS 2010; 2 (2): 4450 .

[12] Tuloro T, Deressa W, Ali A, Davey G. The role of men in contraceptive use and fertility preference in Hossana Town, southern Ethiopia Ethiop J Health Dev. 2006.

[13] Eceh, Chika A." Contraceptive practice in Ghana: Does partner's attitude matter?" paper presented at the annual conference of population association of America, Denver, Colorado, 19th April -2nd may 2008.

[14] Cleland J, Ndugwa R, Zulu E. Family planning in sub-Saharan Africa: progress or stagnation? Bull World Health Organ. 2011; 89 (2): 137-43.

[15] Terefe A, Larson C. Modern contraception use in Ethiopia: does involving husbands make a difference? Am. J Public Health. 2006; 83 (11): 1567-71.

[16] Md. Shahidul M., shaful A. \& Mahedi H. Inter-spousal communication and contraceptive uses, social science. 2014: $10(2)$. 